\title{
Level and predictors of participation in patients with stroke undergoing inpatient rehabilitation
}

\author{
Su-Yin Yang ${ }^{1}$, MSc, Keng He Kong ${ }^{1}$, MBBS, MRcP
}

INTRODUCTION The level of participation is an important factor influencing rehabilitation outcome. However, few studies have evaluated rehabilitation participation and its clinical predictors in patients with stroke. This study aimed to establish the level of participation in patients with stroke undergoing inpatient rehabilitation, and define the clinical predictors for participation.

METHODS This was a prospective observational study of first-time patients with stroke admitted to a rehabilitation centre over a 12-month period. The primary outcome measure was the level of rehabilitation participation as measured on the Pittsburgh Rehabilitation Participation Scale (PRPS). PRPS measurements were made one week after admission and one week before planned discharge from inpatient rehabilitation. Other outcome measures evaluated were the National Institute of Health Stroke Scale, Functional Independence Measure (FIM), Elderly Cognitive Assessment Questionnaire (ECAQ), Centre for Epidemiologic Studies-Depression Scale, Fatigue Severity Scale (FSS), Lubben Social Network Scale-Revised, and Multidimensional Health Questionnaire.

RESULTS A total of 122 patients with stroke were studied. The mean PRPS score on admission was relatively high at $4.30 \pm 0.90$, and this improved to $4.65 \pm 0.79$ before planned discharge $(p<0.001)$. On multivariate analysis, the mean PRPS score on admission was predicted by FIM, EACQ and FSS scores on admission, but not by variables such as age, gender, depression, social support, or health attitudes and beliefs.

CONCLUSION Patients with lower levels of participation were more likely to be functionally dependent, cognitively impaired and have more fatigue. We suggest that in addition to cognition, fatigue should be routinely screened in patients with stroke undergoing rehabilitation.

Keywords: patient participation, rehabilitation, stroke

\section{INTRODUCTION}

In Singapore, stroke is the fourth leading cause of death and a significant cause of disability in the adult population. Among those who survive, a significant proportion will need inpatient rehabilitation because of neurological impairments and disabilities.

One key factor determining successful rehabilitation outcome is patient participation. Lenze et al studied 242 elderly patients with varying diagnoses receiving inpatient rehabilitation and noted that $25 \%$ of them were 'poor participators', as measured on the Pittsburgh Rehabilitation Participation Scale (PRPS). (1) These 'poor participators' stayed in rehabilitation for a long period of time and had worse functional outcome. In a more recent study, Paolucci et al studied 362 patients with stroke or orthopaedic diagnoses admitted to a rehabilitation hospital and found that about one-third of them had low participation. ${ }^{(2)}$ These included those with patientrelated factors such as motivation, depression, cognitive and language impairments, fatigue, as well as social factors such as therapist-patient relationship and family and staff expectations.

It has been established that patients with high motivation and those with low motivation place different emphases on how environmental factors influence their attitude toward rehabilitation. ${ }^{(3)}$ Maclean et al identified differences in high and low participators through a qualitative study conducted on a cohort of 22 patients with stroke undergoing rehabilitation. ${ }^{(4)}$ Patients who were high participators generally understood the necessity for rehabilitation and acknowledged the role of medical professionals in their rehabilitation. They also endorsed the belief that effort was essential to make gains and achieve independence. Low participators, however, endorsed the belief that they had to wait for recovery. These patients often could not understand the nature of rehabilitation exercises, expected things to be done for them and had low initiative to participate. According to other studies, factors that influence patients' beliefs about rehabilitation include overprotection from family members, comparison with other patients, information provided by health professionals and the prevalence of mixed messages. ${ }^{(5,6)}$

To the best of our knowledge, no study has looked at the problem of participation and its clinical correlates in patients with stroke undergoing inpatient rehabilitation in the Singaporean population. Thus, this study sought to establish the level of participation in patients with stroke admitted to an inpatient rehabilitation programme and identify the clinical predictors of patient participation.

${ }^{1}$ Department of Rehabilitation Medicine, Tan Tock Seng Hospital, Singapore

Correspondence: Dr Keng He Kong, Senior Consultant, Department of Rehabilitation Medicine, Tan Tock Seng Hospital, c/o Ang Mo Kio Hospital, 17 Ang Mo Kio Ave 9, Singapore 569766. keng_he_kong@ttsh.com.sg 


\section{METHODS}

This was a prospective observational cohort study of patients with stroke admitted for inpatient rehabilitation at the rehabilitation centre in the Department of Rehabilitation Medicine, Tan Tock Seng Hospital (TTSH), Singapore, over a 12-month period between January 2008 and December 2008. The patients were referred by the neurological service at the hospital and were screened by a rehabilitation physician before acceptance into the rehabilitation unit. The inclusion criteria were: (a) patients aged $\geq 21$ years; and (b) patients with a first ischaemic or haemorrhagic stroke (confirmed on either computed tomography or magnetic resonance imaging). The exclusion criteria were: (a) patients who were premorbidly functionally dependent, defined by a modified Rankin Scale score of $\geq 3$; (b) patients with a history of dementia or neurological disease known to affect cognition; and (c) patients with recurrent stroke. Patients who fulfilled the criteria were invited to participate in the study. Written informed consent was obtained according to the Good Clinical Practice guidelines. ${ }^{(7)}$ Ethical approval to conduct the study was granted by the National Healthcare Group Domain Specific Review Board.

The rehabilitation programme consisted of two hours of therapy (one hour of occupational therapy and one hour of physical therapy) daily, from Monday to Friday. Other rehabilitation interventions, including speech and language therapy, as well as psychological evaluation and counselling, were provided on a need-to basis.

The following instruments were administered for evaluation:

1. PRPS was used to assess the level of participation. ${ }^{(1)}$ This is a six-point Likert-type measure of observed patient participation in a therapy session. It is scored by the treating therapist, with 1 indicating no participation and 6 implying excellent participation. It has been validated in patients undergoing inpatient rehabilitation, including those with stroke. ${ }^{(1)}$ Only data on the level of participation in occupational and physical therapy was captured. Participation in speech and language therapy was not rated, as not all patients required this form of therapy. All therapists involved in the study underwent consensus training on the use of the PRPS. As it is simple to use, the therapists required minimal training.

2. National Institute of Health Stroke Scale (NIHSS) was used to measure neurological impairment. ${ }^{(8)}$ This 42-point ordinal scale, frequently used in stroke studies, measures neurological deficit, including consciousness, hemianopia, sensation, neglect and language.

3. Elderly Cognitive Assessment Questionnaire (ECAQ) was used to determine the level of cognition. ${ }^{(9)}$ This ten-item questionnaire, which evaluates the patient's orientation and memory, has been validated locally. ${ }^{(9)}$ A score of $<8$ indicates possible cognitive impairment.

4. Functional Independence Measure (FIM) was used to assess independence in activities of daily living. ${ }^{(10)}$ This is an 18-item ordinal scale that measures the patient's functional status.

5. Centre for Epidemiologic Studies-Depression Scale (CES-D) was used to screen for depression. ${ }^{(11)}$ This is a self-report scale, designed to measure depressive symptoms, that has been validated in patients with stroke. ${ }^{(12)}$ A score of $\geq 16$ indicates the presence of depressive symptoms.

6. Fatigue Severity Scale (FSS) was used to assess fatigue. ${ }^{(13)}$ The FSS has been validated in patients with stroke, and it scores from 0 to 7 - the higher the score, the greater the fatigue.

7. Lubben Social Network Scale-Revised (LSNS-R) ${ }^{(14)}$ consists of an equally weighted sum of 12 items used to measure the size, closeness and frequency of contacts in a respondent's social network, which differentiates the level of perceived support received from family and friends in two separate categories. The total score is obtained by adding all the ratings on each of the 12 items - the higher the score, the greater the level of social support.

8. Multidimensional Health Questionnaire $(\mathrm{MHQ})^{(15)}$ was used to assess the patient's health attitudes and beliefs. Although the original questionnaire contained 20 subscales, only the following five subscales were chosen for this study: health-efficacy, chance-luck health control, health expectations-optimism, powerful-other health control and internal health control. Each subscale contained five items. Patients were rated on a 5-point Likert scale, according to how much they believed each statement to be true. The total score for each subscale was obtained by adding the ratings for each statement. The higher the rating, the more likely the respondent's adherence to the belief statement of that subscale.

NIHSS, ECAQ, FIM, FSS, CES-D, LSNS-R and MHQ were evaluated within 72 hours of admission. PRPS was evaluated daily in the first week of admission and one week before planned discharge. For patients with severe dysphasia or cognitive impairments, CES-D, FSS, LSNS-R and MHQ were omitted. Other data captured included each patient's demographic variables and length of stay in rehabilitation. Except for FSS, LSNS-R and MHQ, all other data for this study was collected as part of the patients' initial assessment.

The outcome measures of interest were the mean PRPS scores in the first week of admission and the week before planned discharge. The former was calculated by dividing the total PRPS score in the first week by the number of occupational and physical therapy sessions. The PRPS scores for the week before planned discharge were similarly obtained by dividing the total PRPS scores in the week before discharge by the number of therapy sessions. As some patients might have received more therapy sessions than others, averaging of the PRPS score was done to ensure that this potential confounder was eliminated. The following variables were studied for their 
predictive potential of admission PRPS scores: age, gender, and NIHSS, ECAQ, FIM, CES-D, FSS, LSNS-R and MHQ scores on admission.

Statistical analysis was performed using the Statistical Package for the Social Sciences for Windows version 14 (SPSS Inc, Chicago, IL, USA). All statistical tests were carried out at $5 \%$ level of significance. Parametric tests were used. Pearson's correlation was used for the correlation of variables. Student's $t$-test was used for the comparison of means of independent variables as well as for the comparison of PRPS and FIM scores on admission and at discharge. Predictive variables that were significant on univariate analysis were subjected to stepwise multiple regression analysis. The predictive potential of admission PRPS scores on discharge FIM score and rehabilitation length of stay was also assessed.

\section{RESULTS}

Consecutive patients with stroke $(\mathrm{n}=122)$ were recruited from the rehabilitation unit at TTSH. The CES-D, FSS, LSNS-R and MHQ instruments were not administered for seven patients due to the presence of significant language and/or cognitive deficits. The study cohort was relatively young, with a mean age of $58.20 \pm 10.50$ years. The majority of participants were of Chinese ethnicity, a finding consistent with the overall ethnic distribution of Singapore. The mean length of stay in rehabilitation was $23.5 \pm 11.2$ days. The baseline characteristics of the patients with stroke are shown in Table I.

Generally, the patients did not have severe neurological impairments on admission to rehabilitation, as suggested by the low mean NIHSS score $(6.50 \pm 4.50)$ on admission. Depression was not common, with only 15 out of 115 eligible patients (13\%) categorised as depressed based on CES-D scores of $\geq 16$. The mean LSNS-R score of $36.10 \pm 11.00$ indicated that the majority of patients had good social support with low risk of isolation. The mean PRPS score on admission was relatively high at $4.30 \pm 0.90$, and this improved to $4.65 \pm 0.79$ on discharge. The difference between PRPS scores on admission and at discharge was statistically significant $(p<0.001)$.

Results of the univariate analysis of variables predicting PRPS scores on admission are shown in Table II. The PRPS score on admission did not correlate with age, gender, and LSNS-R and MHQ scores. The PRPS score, however, showed positive correlation with FIM and ECAQ scores on admission, and negative correlation with NIHSS, CES-D and FSS scores on admission. On multivariate regression, only FIM ( $p=0.002)$, FSS $(p=0.002)$ and ECAQ $(p=0.01)$ scores remained statistically significant predictors of PRPS score on admission (Table III). PRPS score on admission was negatively correlated with the length of stay in rehabilitation $(r=-0.23, p=0.012)$ and FIM score at discharge $(r=0.40, p<0.001)$.
Table I. Baseline characteristics of the patients with stroke ( $n=122)$.

\begin{tabular}{|c|c|}
\hline Variable & No. of patients \\
\hline Age* (yrs) $^{*}$ & $58.20 \pm 10.50$ \\
\hline $\begin{array}{l}\text { Gender } \\
\text { Male } \\
\text { Female }\end{array}$ & $\begin{array}{l}72 \\
50\end{array}$ \\
\hline $\begin{array}{l}\text { Ethnicity } \\
\text { Chinese } \\
\text { Malay } \\
\text { Indian } \\
\text { Others }\end{array}$ & $\begin{array}{r}90 \\
13 \\
11 \\
8\end{array}$ \\
\hline $\begin{array}{l}\text { Type of stroke } \\
\text { Infarct } \\
\text { Haemorrhage }\end{array}$ & $\begin{array}{r}112 \\
10\end{array}$ \\
\hline $\begin{array}{l}\text { Site of stroke } \\
\text { Cortical } \\
\text { Subcortical }\end{array}$ & $\begin{array}{l}54 \\
68\end{array}$ \\
\hline $\begin{array}{l}\text { Side of hemiplegia } \\
\text { Left } \\
\text { Right }\end{array}$ & $\begin{array}{l}65 \\
57\end{array}$ \\
\hline $\begin{array}{l}\text { Score on admission* } \\
\text { PRPS } \\
\text { NIHSS } \\
\text { ECAQ } \\
\text { FIM } \\
\text { CES-D } \\
\text { FSS }\end{array}$ & $\begin{array}{c}4.30 \pm 0.90 \\
6.50 \pm 4.50 \\
8.31 \pm 1.45 \\
68.00 \pm 19.40 \\
9.50 \pm 6.20 \\
3.92 \pm 1.45\end{array}$ \\
\hline LSNS-R score* & $36.10 \pm 11.00$ \\
\hline $\begin{array}{l}\text { MHQ subscale score* } \\
\text { Health-efficacy } \\
\text { Chance-luck health control } \\
\text { Health expectations-optimism } \\
\text { Powerful-other health control } \\
\text { Internal health control }\end{array}$ & $\begin{array}{l}14.80 \pm 6.20 \\
11.30 \pm 8.80 \\
12.30 \pm 8.30 \\
10.50 \pm 10.30 \\
16.70 \pm 8.80\end{array}$ \\
\hline
\end{tabular}

*Data is presented as mean + standard deviation.

CES-D: Centre for Epidemiological Study-Depression Scale; ECAQ: Elderly Cognitive Assessment Questionnaire; FIM: Functional Independence Measure FSS: Fatigue Severity Scale; LSNS-R: Lubben Social Network Scale-Revised; MHQ: Multidimensional Health Questionnnaire; NIHSS: National Institute of Health Stroke Scale; PRPS: Pittsburgh Rehabilitation Participation Scale

\section{DISCUSSION}

To the best of our knowledge, few studies have documented patient participation in inpatient stroke rehabilitation programmes. The level of participation was generally high in our study, as evidenced by the mean admission PRPS score of $4.30 \pm 0.90$ (a score of 4 indicates good participation). One important reason for this finding was that all patients were prescreened by a rehabilitation physician for rehabilitation potential prior to admission to our rehabilitation centre. Although there were no strict guidelines on the definition of rehabilitation potential, these were likely to include medical stability, the perceived ability to participate in therapy, and the presence of an appropriate discharge placement and care plan. Therefore, patients with factors conventionally thought to be associated with poor rehabilitation outcome such as old age, cognitive impairment and depression were less likely to be selected for admission to the centre. This might also explain the relatively low mean age (i.e. 58.2 years) of the patients included in the study, the high mean ECAQ score on admission, 
Table II. Univariate analysis of predictors of the Pittsburgh Rehabilitation Participation Scale score on admission.

\begin{tabular}{|c|c|c|c|c|}
\hline \multirow[t]{2}{*}{ Variable } & \multicolumn{2}{|c|}{ On admission } & \multicolumn{2}{|c|}{ At discharge } \\
\hline & $\mathbf{r}^{*} / \mathrm{df}(t \text {-value })^{+}$ & p-value & $r^{*} /$ df $(t \text {-value })^{+}$ & p-value \\
\hline Age* & -0.15 & 0.081 & -0.11 & 0.24 \\
\hline $\begin{array}{l}\text { Gender }^{+} \\
\text {Male } \\
\text { Female }\end{array}$ & $\begin{array}{l}4.38(0.96) \\
4.34(0.82)\end{array}$ & 0.77 & $\begin{array}{l}4.69(0.81) \\
4.59(0.78)\end{array}$ & 0.78 \\
\hline $\begin{array}{l}\text { Site of stroke } \\
\text { Cortical } \\
\text { Subcortical }\end{array}$ & $\begin{array}{l}4.21(0.86) \\
4.49(0.92)\end{array}$ & 0.089 & $\begin{array}{l}4.57(0.78) \\
4.71(0.80)\end{array}$ & 0.34 \\
\hline $\begin{array}{l}\text { Scores on admission }{ }^{+} \\
\text {NIHSS } \\
\text { FIM } \\
\text { ECAQ } \\
\text { CES-D } \\
\text { FSS }\end{array}$ & $\begin{array}{l}-0.27 \\
0.53 \\
0.35 \\
-0.022 \\
-0.40\end{array}$ & $\begin{array}{r}0.003 \\
<0.001 \\
<0.001 \\
0.021 \\
<0.001\end{array}$ & $\begin{array}{r}-0.18 \\
0.40 \\
0.23 \\
-0.07 \\
-0.36\end{array}$ & $\begin{aligned} & 0.043 \\
< & 0.001 \\
& 0.015 \\
& 0.46 \\
< & 0.001\end{aligned}$ \\
\hline $\begin{array}{l}\text { MHQ subscale score* } \\
\text { Health-efficacy } \\
\text { Chance-luck health control } \\
\text { Health expectations-optimism } \\
\text { Powerful-other health control } \\
\text { Internal health control }\end{array}$ & $\begin{array}{r}0.07 \\
-0.04 \\
0.07 \\
0.12 \\
0.11\end{array}$ & $\begin{array}{l}0.49 \\
0.63 \\
0.41 \\
0.09 \\
0.22\end{array}$ & $\begin{array}{r}0.01 \\
-0.03 \\
0.08 \\
0.07 \\
0.09\end{array}$ & $\begin{array}{l}0.76 \\
0.79 \\
0.35 \\
0.48 \\
0.45\end{array}$ \\
\hline
\end{tabular}

*Pearson's correlation test 'Student's t-test

CES-D: Centre for Epidemiological Study-Depression Scale; df: degrees of freedom; ECAQ: Elderly Cognitive Assessment Questionnaire; FIM: Functional Independence Measure; FSS: Fatigue Severity Scale; LSNS-R: Lubben Social Network Scale-Revised; MHQ: Multidimensional Health Questionnnaire; NIHSS: National Institute of Health Stroke Scale

Table III. Stepwise multiple regression analysis of factors predicting PRPS scores on admission.

\begin{tabular}{lcc}
\hline Score on admission & Standardised coefficient & p-value \\
\hline FIM & 0.309 & 0.002 \\
ECAQ & 0.249 & 0.01 \\
FSS & -0.304 & 0.002 \\
\hline
\end{tabular}

ECAQ: Elderly Cognitive Assessment Questionnaire; FIM: Functional Independence Measure; FSS: Fatigue Severity Scale; PRPS: Pittsburgh Rehabilitation Participation Scale

the low number of patients with depression, and the generally good social support enjoyed by our patients (as evidenced by a high mean LSNS-R score of 36.1). Although the mean PRPS score improved to $4.65 \pm 0.79$ at discharge and the difference was statistically significant when compared to PRPS scores on admission, it is debatable whether this finding has any clinical implications.

Even in a group of preselected patients with stroke, we were able to show that the level of participation on admission among patients undergoing inpatient rehabilitation was significantly predicted by three independent factors. The first factor is functional status, as measured by FIM score. Poor functional status as a predictor of participation has previously been reported.(1) Lenze et al, who studied 242 inpatients with varying impairments (including stroke) in a university-based, freestanding acute rehabilitation hospital, found that FIMmotor score on admission was the most important correlate of PRPS score. ${ }^{(1)}$ The mean admission PRPS score of $4.7 \pm 0.8$ in their study cohort is not much different from that of our study. Lenze et al also reported that PRPS score on admission predicted rehabilitation outcome and length of stay in rehabilitation - patients with lower PRPS scores stayed in rehablilitation for a longer period of time and made fewer gains in FIM scores. This finding was also replicated in our study.

The second factor predicting rehabilitation participation is cognitive impairment, as measured on ECAQ. Cognitive impairment has been identified in previous studies as a negative predictor of functional outcome in patients with stroke under-going inpatient rehabilitation, ${ }^{(16,17)}$ and this could be due to its impact on participation, as demonstrated in our study. It is likely that cognitive impairments limit the patient's ability to understand or recall instructions, initiate recommended exercises or self-direct their rehabilitation programme. The impact of specific domains of cognitive impairments on rehabilitation participation in patients with stroke was recently studied by Skidmore et al, who evaluated the attention, memory and executive functions of 44 patients with stroke undergoing inpatient rehabilitation. ${ }^{(18)}$ The authors found that executive function was the only cognitive domain that predicted rehabilitation participation.

The final factor predicting participation is fatigue, as measured using FSS. In our study, patients with higher FSS scores showed poorer participation in rehabilitation. Fatigue after stroke is common, with a reported frequency of $38 \%-77 \%$, and $40 \%$ of patients perceive it to be one of the worst sequelae of stroke. ${ }^{(19,20)}$ Many factors have been reported to be associated with fatigue, including age, depression, reduced physical fitness and infratentorial infarct. ${ }^{(21-24)}$ Fatigue can also be caused by medical comorbidities (e.g. anaemia and impaired cardio-respiratory function) and drugs (e.g. beta blockers), although these factors were not evaluated in our study. 
A patient's health attitudes and beliefs may also influence motivation and participation. Mold et al reviewed 55 qualitative research articles that assessed processes in stroke rehabilitation that are specific to social influences on participation. ${ }^{(25)}$ The articles reviewed focused on the perspectives of both professionals and patients. The authors concluded that the ways in which healthcare professionals and patients perceive their involvement in rehabilitation, and the manner in which they viewed each other, influenced doctor-patient interactions and thereby rehabilitation outcomes. In our study, although we did not examine the interactions between healthcare professionals and patients, we did assess patient attitudes and health beliefs. However, we were unable to demonstrate any correlation between the level of participation in rehabilitation and the health attitudes and beliefs of patients, as measured on the five MHQ subscales.

This study is not without limitations. Firstly, the preselection of patients for rehabilitation is likely to have biased the sample against the inclusion of poor participators into the programme. Our findings may also not be generalisable to the entire Singapore population, as our sample was recruited from only one rehabilitation centre. It is possible that collating data from other centres may yield differing results. Secondly, poor patient-therapist relationships and subjective observations of participation by therapists could have biased the PRPS scores that these therapists recorded. For instance, if a therapist were to deem a patient to be a poor participator within the first week of admission, this perception would likely not have changed later on. It should be noted that although some patients, on occasion, had more than one therapist conducting therapy during their inpatient stay, there was only one rater per professional group (occupational or physical therapy) most of the time. Hypothesising that patients might prefer to relearn how to walk and hence be more participative in physiotherapy, we assessed whether patients would project and place different emphases on occupational and physical therapies. However, our findings suggest that the variability in frequency or average scores across ratings by both types of therapists was minimal, indicating that patients performed just as well in both sessions.

In conclusion, the level of participation in rehabilitation on admission and before discharge in our cohort of 122 patients with stroke receiving inpatient rehabilitation was generally good. Efforts should be made to identify patients who are likely to be poor participators, such as those with poor functional status, cognitive impairment and fatigue, as some of the underlying conditions associated with these factors are potentially treatable.

\section{REFERENCES}

1. Lenze EJ, Munin MC, Quear T, et al. The Pittsburgh Rehabilitation Participation Scale: reliability and validity of a clinician-rated measure of participation in acute rehabilitation. Arch Phys Med Rehabil 2004; 85:380-4

2. Paolucci S, Di Vita A, Massicci R, et al. Impact of participation on rehabilitation results: a multivariate study. Eur J Phys Rehabil 2012; 48:455-66.

3. Holmqvist LW, von Koch L. Environmental factors in stroke rehabilitation. BMJ 2001; 322:1501-2.

4. Maclean N, Pound P, Wolfe C, Rudd A. Qualitative analysis of stroke patients' motivation for rehabilitation. BMJ 2000; 321:1051-4.

5. Teasell RW, Kalra L. What's new in stroke rehabilitation: back to basics. Stroke 2005; 36:215-7.

6. Kalra L, Evans A, Perez I, et al. Training carers of stroke patients: randomised controlled trial. BMJ 2004; 328:1099.

7. $\mathrm{ICH}$ harmonised tripartite guideline: guideline for good clinical practice. 8. Essential documents for the conduct of a clinical trial. J Postgrad Med 2001; 47:264.

8. Brott T, Adams HP Jr, Olinger CP, et al. Measurements of acute cerebral infarction: a clinical examination scale. Stroke 1989; 20:864-70.

9. Kua, EH, Ko SM. A questionnaire to screen for cognitive impairment among elderly people in developing countries. Acta Psychiatr Scand 1992; 85:119-22.

10. Keith RA, Granger CV, Hamilton BB, Sherwin FS. The functional independence measure: a new tool for rehabilitation. In: Eisenberg MG, Grzesiak RC, eds. Advance in Clinical Rehabilitation volume 1. New York: Springer-Verlag, 1987: 6-18.

11. Radloff LS. The CES-D scale: A self-report depression scale for research in the general population. Appl Psychol Measures 1977; 1:385-401.

12. Shinar D, Gross CR, Price TR, et al. Screening for depression in stroke patients: the reliability and validity of the Center for Epidemiological Studies Depression Scale. Stroke 1986; 17:241-5.

13. Krupp LB, LaRocca G, Muir-Nash J, Steinberg AD. The fatigue severity scale. Application to patients with multiple sclerosis and systemic lupus erythematosus. Arch Neurol 1989; 46:1121-3.

14. Lubben J, Gironda M, Lee A. Refinements to the Lubben Social Network Scale: The LSNS-R. The Behavioural Measurements Letter 2001; 7:2-11.

15. Snell WE Jr, Johnson G. The Multidimensional Health Questionnaire. Am J Health Behav 1997; 21:33-42.

16. Heruti RJ, Lusky A, Danker R, et al. Rehabilitation outcome of elderly patients after a first stroke: effect of cognitive status at admission on the functional outcome. Arch Phys Med Rehabil 2002; 83:742-9.

17. Hakkennes SJ, Brock K, Hill KD. Selection for inpatient rehabilitation after acute stroke: a systematic review of the literature. Arch Phys Med Rehabil 2011; 92:2057-70.

18. Skidmore ER, Whyte EM, Holm MB, et al. Cognitive and affective predictors of rehabilitation participation after stroke. Arch Phys Med Rehabil 2010; 91:203-7.

19. Lerdal A, Bakken LN, Kouwenhoven SE, et al. Poststroke fatigue-a review. J Pain Symptom Manage 2009; 38:928-49.

20. Ingles JL, Eskes GA, Phillips SJ. Fatigue after stroke. Arch Phys Med Rehabil 1999; 80:173-8.

21. Snaphaan L, van der Werf S, de Leeuw FE. Time course and risk factors of post-stroke fatigue: a prospective cohort study. Eur J Neurol 2011; 18:611-7.

22. Glader EL, Stegmayr B, Asplund K. Poststroke fatigue: a 2-year follow-up study of stroke patients in Sweden. Stroke 2002; 33:1327-33.

23. Tseng BY, Billinger SA, Gajewski BJ, Kluding PM. Exertion fatigue and chronic fatigue are two distinct constructs in people post-stroke. Stroke 2010; 41:2908-12.

24. Naess H, Nyland HI, Thomassen L, Aarseth J, Myhr KM. Fatigue at longterm follow-up in young adults with cerebral infarction. Cerebrovasc Dis 2005; 20:245-50.

25. Mold F, McKevitt C, Wolfe C. A review and commentary of the social factors which influence stroke care: issues of inequality in qualitative literature. Health Soc Care Community 2003; 11:405-14. 